
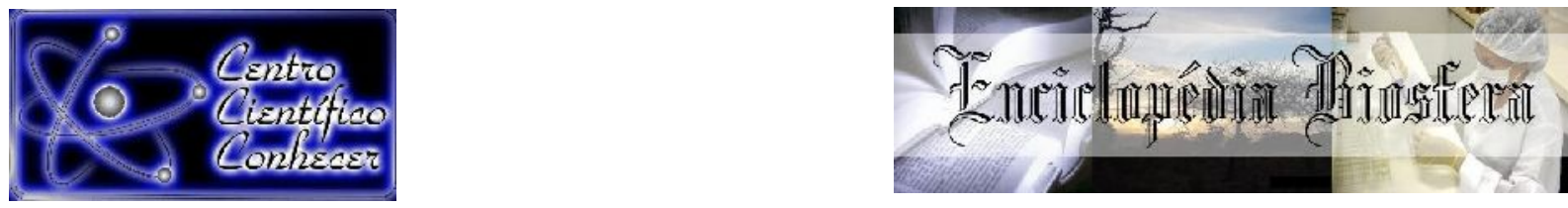

\title{
COMPLEXO GRANULOMA EOSINOFÍLICO FELINO
}

Gabriele Barros Mothé1; Caroline Scott ${ }^{2}$; Rafael Barros Mothé ${ }^{3}$; Janas D’arc Barros Siqueira ; Aguinaldo Francisco Mendes Junior ${ }^{5}$

${ }^{1}$ Médica veterinária e docente da Universidade Santa Úrsula e da Universidade de Vassouras - Campus Maricá, Rio de Janeiro, RJ, Brasil. Autora correspondente: gbmothe@usu.edu.br

2Médica veterinária e doutora pela Universidade Estadual Paulista, Botucatu, SP, Brasil.

${ }^{3}$ Engenheiro ambiental e sanitário pela Universidade Estácio de Sá, Macaé, RJ, Brasil.

${ }^{4}$ Engenheira de produção pela Universidade Salgado de Oliveira, São Gonçalo, RJ, Brasil.

${ }^{5}$ Médico veterinário e docente da Universidade Santa Úrsula, Rio de Janeiro, RJ, Brasil.

\section{Recebido em: 15/11/2020 - Aprovado em: 15/12/2020 - Publicado em: 30/12/2020}

DOI: 10.18677/EnciBio_2020D8

O complexo granuloma eosinofílico felino (CGEF) é chamado de complexo pois é uma síndrome, clinicamente com três formas típicas: Granuloma eosinofílico (GE), placa eosinofílica (PE) e úlcera indolente (UI). O primeiro ainda é subdividido em: granuloma linear (GL), granuloma do mento (GM) e granuloma orofaríngeo nodular (GON). Essas formas são semelhantes, principalmente no que se refere às características histológicas das lesões, mas com topografia diversa no corpo, e têm variados aspectos, dor e prurido. Ainda assim, são agrupadas na forma de complexo por facilitar o diagnóstico e, consequentemente, o tratamento. A etiologia ainda não está bem estabelecida e o diagnóstico é um desafio, pois geralmente está relacionada com uma outra doença de base, além de também ser possível a ocorrência simultânea de mais de uma forma da doença. Baseado nisso, o objetivo desse trabalho foi revisar informações a respeito dessa síndrome em gatos, devido a escassa literatura sobre o tema e os desafios relacionados a etiologia multifatorial, a patogenia, os diferentes padrões clínicos, o diagnóstico da doença primária, e assim, contribuir para a diminuição dos casos de falhas terapêuticas.

PALAVRAS-CHAVE: Dermatopatia. Eosinófilo. Gato. Pele. Síndrome. 


\title{
EOSINOPHILIC GRANULOMA FELINE COMPLEX
}

\begin{abstract}
Eosinophilic Granuloma Feline Complex (CGEF) is called a complex because it is a syndrome, manifested clinically through three typical forms: Eosinophilic Granuloma $(\mathrm{GE})$, Eosinophilic Plaque (PE) and Indolent Ulcer (UI). The first is further subdivided into: Linear Granuloma (GL), Ment Granuloma (GM) and Granuloma Oropharyngeal Nodular (GON). These shapes are similar, especially histological characteristics of the lesions, but with a different topography on the body, and have different aspects, pain and pruritus. Even so, they ate grouped in the form of complex for facilitating the diagnosis and, consequently, the treatment. The etiology is not yet well established and the diagnosis is a challenge, since it is usually related to another primary disease, in addition to the possibility of the simultaneous occurrence of more than one form of the disease. Based on this, the objective of this study was to review information about this syndrome in cats, due to the scarce literature on the subject and the challenges related to multifactorial etiology, pathogenesis, different clinical patterns, the diagnosis of the primary disease, and thus contribute for the reduction of cases of therapeutic failures.
\end{abstract}

KEYWORDS: Cat. Eosinophil. Skin. Skin disease. Syndrome.

\section{COMPLEJO DE GRANULOMA EOSINOFÍLICO FELINO}

\section{RESUMEN}

El complejo de granuloma eosinofílico felino (CGEF) se denomina complejo porque es un síndrome, clínicamente con tres formas típicas: granuloma eosinofílico (GE), placa eosinofílica (PE) y úlcera indolente (UI). El primero se subdivide en: granuloma lineal (GL), granuloma ment (GM) y granuloma orofaríngeo nodular (GON). Estas formas son similares, especialmente en lo que respecta a las características histológicas de las lesiones, pero con una topografía corporal diferente, y tienen diferentes aspectos, dolor y prurito. Aun así, se agrupan en forma de complejo para facilitar el diagnóstico y, en consecuencia, el tratamiento. La etiología aún no está bien establecida y el diagnóstico es un desafío, ya que generalmente se relaciona con otra enfermedad subyacente, además de la posibilidad de que ocurra simultáneamente más de una forma de la enfermedad. En base a esto, el objetivo de este trabajo fue revisar la información sobre este síndrome en gatos, debido a la escasa literatura sobre el tema y los desafíos relacionados con la etiología multifactorial, patogénesis, diferentes patrones clínicos, el diagnóstico de la enfermedad primaria, y así contribuir para la reducción de casos de fracasos terapéuticos.

PALABRAS CLAVE: Dermatopatía. Eosinófilos. Gato. Piel. Síndrome.

\section{INTRODUÇÃO}

A pele é o maior órgão do corpo e tem várias funções importantes, dentre elas, uma das mais importantes é a proteção contra injúrias físicas, químicas e/ou microbiológicas, pois a pele consiste numa barreira anatômica entre o organismo e o meio ambiente (FEITOSA, 2004; CONCEIÇÃO-SILVA; MORGADO, 2018; ABBAS et al., 2019). Por ser um órgão tão exposto, a pele está propensa a diversas agressões 
e alterações, refletindo na casuística dos atendimentos veterinários, já que as dermatoses apresentam grande prevalência em pequenos animas, reconhecidas como o motivo mais comum para consulta médica veterinária, estando dentre as causas principais de queixas e/ou como doença secundária (HILL et al., 2006).

Estima-se que entre 30 a $75 \%$ dos atendimentos veterinários estão diretamente relacionados às doenças dermatológicas (FEITOSA, 2004), e as causas mais frequentes de dermatopatia nessas espécies têm origem infecciosa, alérgica, hormonal, psicogênica ou multifatorial. As dermatoses alérgicas são as mais frequentes em gatos e o CGEF compreende uma das mais comuns manifestações de doenças alérgica nessa espécie (BUCKLEY; NUTTALL, 2012; CERDEIRO et al., 2015; LARSSON; LUCAS, 2016). No entanto, apesar dos avanços na dermatologia felina, o CGEF é ainda pouco compreendido (BUCKEY; NUTTALL, 2012).

Como já mencionado, o CGEF é constituído por um grupo de doenças cutâneas, primariamente com base em suas semelhanças clínicas e desenvolvimento simultâneo frequente (BUCKLEY; NUTTALL, 2012; MAZZOTTI; ROZA, 2016). Todas as formas do CGEF (PE, UI, GE, GL, GM, GON) ocorrem devido a uma resposta exacerbada e inesperada de eosinófilos e mastócitos, induzidos por um distúrbio de hipersensibilidade, causando lesões na pele (BLOOM, 2006; TAGLINGER et al., 2007).

A doença pode ocorrer por vários fatores, ter uma doença inicial e várias formas clínicas do complexo no mesmo indivíduo, tornando o diagnóstico um desafio e atrasando tratamento (MAZZOTTI; ROZA, 2016; BRITO, 2017).

O tratamento é feito baseado no diagnóstico da doença de base, com uso principalmente de corticoides e antimicrobianos, além de outras opções terapêuticas, em casos recidivantes (HNILICA, 2011; CERDEIRO et al., 2015; LARSSON; LUCAS, 2016; MAZZOTTI; ROZA, 2016).

\section{- TERMINOLOGIA}

O termo CGEF é o mais empregado (MILLER et al., 2013), mas existem outros termos utilizados para designá-lo, como "doença de pele eosinofílica felina" e "dermatose eosinofílica" pois nem sempre as lesões são granulomatosas (POWER; IHRKE, 1995; BLOOM, 2006). Em cães, tal doença é referida apenas como CGE (HASAN et al., 2016).

Os diferentes padrões de manifestação clínica também são descritos com diferentes nomes, como a seguir: UI também se denomina "úlcera eosinofílica" ou "úlcera dos roedores" ou "dermatite ulcerativa do lábio superior felina"; e o GE também pode ser denominado "granuloma linear" ou "granuloma colagenolítico" (FOSTER, 2003).

\section{- PATOGENIA}

O CGEF ocorre inicialmente devido a uma resposta exacerbada de eosinófilo (daí a origem do nome) e mastócitos, estimulados por uma reação de hipersensibilidade. Como os eosinófilos participam do sistema imunológico, essa resposta resulta na liberação de potentes agentes inflamatórios contra algum corpo estranho, provocando, por fim, as dermatopatias (BLOOM, 2006; TAGLINGER et al., 2007). 
Várias moléculas podem ativar e atrair os eosinófilos, como as quimiocinas, citocinas, mediadores de lipídios, sistema complemento, imunoglobulinas, entre outros, que atraem os eosinófilos para o local alvo para que eles possam destruir antígenos. Mas, essas células só fagocitam antígenos pequenos (BLOOM, 2006). Quando estão diante de grandes parasitas, os eosinófilos sofrem e granulação e liberam proteínas e enzimas, causando então destruição tecidual e inflamação, que resultam em prurido, eritema e pápulas (BLOOM, 2006). Ou seja, algum fator, geralmente de hipersensibilidade, estimula inadequadamente os eosinófilos, que então ocasionam uma inflamação que se reflete em alterações dermatológicas (BLOOM, 2006; TAGLINGER et al., 2007).

\section{- ETIOLOGIA}

A etiologia do CGEF é fonte de muitos estudos e não está completamente elucidada. Geralmente, a síndrome está associada a uma causa alérgica, mas outras etiologias são possíveis, como infecções virais e bacterianas, doenças autoimunes, predisposição genética e hereditária, e pode ter também caráter idiopático (Tabela 1) (BLOOM, 2006; BARBOSA et al., 2013; CERDEIRO et al., 2015; LARSSON; LUCAS, 2016; MAZZOTTI; ROZA, 2016). Porém, são lesões mais comumente encontradas em animais que já têm histórico de hipersensibilidade a inalantes, alimentos ou insetos, particularmente pulgas e mosquitos (MILLER et al., 2013).

QUADRO 1: Fatores etiológicos associados ao CGEF (SANTOS, 2013 adaptado).

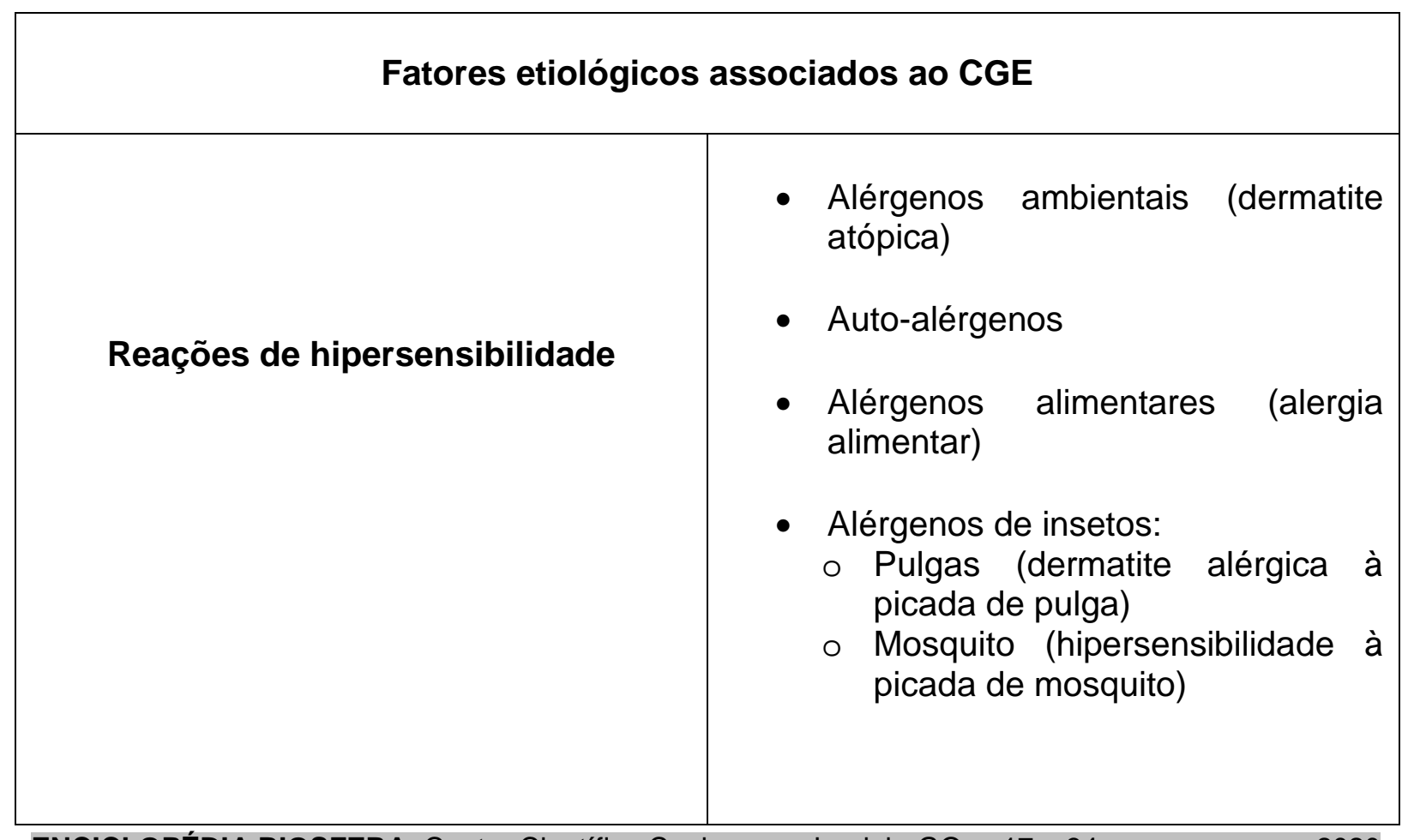




\begin{tabular}{|c|c|}
\hline Doenças infecciosas & $\begin{array}{l}\text { - Virais: } \\
\circ \text { Herpes vírus tipo I felino } \\
\circ \text { Vírus de imunodeficiência felina } \\
\circ \text { Vírus da leucemia felina } \\
\text { - Bacterianas } \\
\text { - Fúngicas } \\
\text { ○ Dermatofitose } \\
\text { - Parasitárias } \\
\text { - Sarna notoédrica } \\
\circ \text { Pediculose } \\
\circ \text { Demodicose }\end{array}$ \\
\hline Genética & $\begin{array}{l}\text { - Desregulação hereditária de } \\
\text { eosinófilos }\end{array}$ \\
\hline Idiopática & $\begin{array}{l}\text { - Quando todas as outras causas } \\
\text { são descartadas e a etiologia é } \\
\text { desconhecida }\end{array}$ \\
\hline
\end{tabular}

Fonte: Santos, (2013)

O CGEF pode ter origem autoimune: um estudo realizado em 19 gatos acometidos por no mínimo uma das formas clínicas do complexo, mostrou que 13 deles tinham anticorpos circulantes contra o epitélio normal, sugerindo uma reação imune que seria responsável pelas alterações dermatológicas (GELBERD et al., 1985). Também pode ter origem genética, como foi demonstrado em um trabalho em que vários gatos da mesma família apresentaram GE e UI sem que testes intradérmicos e dietas de exclusão indicassem alergia primária, indicando um descontrole genético e hereditário dos eosinófilos e predispondo tais animais às reações cutâneas (POWER, 1990).

A dermatite alérgica à picada de pulga (DAPP) é a principal causa de PE (LEE GROSS et al., 2005), além disso, a indução experimental desse tipo de reação de hipersensibilidade aplicada em oito gatos, provocou sinais clínicos de alergia em cinco e, destes, todos desenvolveram úlceras indolentes (COLOMBINI et al., 2001). Além da DAPP, ainda podem ocorrer a dermatite atópica (devido à hipersensibilidade a antígenos ambientais) e a alergia alimentar (cuja reação adversa a um alimento ou aditivo alimentar, além de causar lesões cutâneas típicas do CGEF, também pode causar sinais gastrointestinais) (HNILICA, 2011).

Agentes infecciosos também podem causar o CGEF, como por exemplo vírus, mas raramente o CGEF está associado à uma infecção viral (MILLER et al., 2013). ENCICLOPÉDIA BIOSFERA, Centro Científico Conhecer - Jandaia-GO, v.17 n.34; p. 102 
Bactérias também podem ter relação com o CGEF e inclusive já foram identificadas em alguns casos. Apesar disso, é provável que estas tenham sido identificadas por acaso, como oportunistas, já que não se espalham pelo corpo, para outras regiões, ficando restritas às lesões do CGEF (MORIELLO et al., 1990).

\section{- EPIDEMIOLOGIA}

A epidemiologia para o desenvolvimento das lesões do CGEF também não está completamente elucidada. Segundo Buckley e Nuttall (2012) não existe predisposição racial para o desenvolvimento das lesões do CGEF, mas Feitosa (2004) sugere que gatos da raça siamês sejam mais propensos a desenvolverem um dos padrões da doença.

Quanto ao sexo, Medleau e Hnilica (2009) indicam que não existe predisposição, já Paterson (2010) e Buckley e Nuttall (2012) acreditam que, por serem mais acometidas do que os machos, as gatas são mais predispostas.

Em relação à predisposição etária, o CGEF pode ocorrer em uma ampla faixa etária. Por exemplo, na forma do GE, ocorre com maior frequência em animais novos, com até dois anos ou de meia idade (PATERSON, 2010; BARBOSA et al., 2013), como ocorre também na manifestação da PE que afeta felinos de dois a seis anos de idade. Enquanto as UI estão presentes em animais de qualquer faixa etária (FOSTER, 2003).

O CGEF tem ocorrência comum e incidência sazonal, principalmente nas épocas que propiciam maior proliferação de insetos picadores, como pulgas e mosquitos (BUCKLEY; NUTTALL, 2012).

Apesar de se tratar de uma doença frequente em gatos, o CGEF, e as suas diferentes apresentações clínicas, ainda é pouco referenciado na literatura brasileira. Internacionalmente, em um estudo incluindo 783 animais, o CGEF foi diagnosticado em $72(9,2 \%)$ gatos acometidos por alguma alteração dermatológica, sendo, no que diz respeito as dermatopatias alérgicas, superior aos acometidos por dermatite atópica $(2,4 \%)$ e alergia alimentar $(2,8 \%)$, e inferior aos acometidos por hipersensibilidade a picada de pulga (22,3\%) (BOURDEAU; FER, 2004). Em outros estudos, em uma amostragem de 154 gatos com enfermidades dermatológicas, o CGEF ocupou o sexto lugar das mais comuns (HILL et al., 2006) e entre 1407 casos, o nono lugar (SCOTT et al., 2012).

\section{- SINTOMATOLOGIA CLÍNICA}

Como já mencionado, as diferentes formas clínicas do CGEF são reunidas em um complexo porque compartilham características, principalmente no que diz respeito à histologia, apresentando, invariavelmente, infiltrado de eosinófilos. Além disso, também pode apresentar outras células, como mastócitos, histiócitos e linfócitos, e também fibras de colágeno com eosinófilos degranulados em volta, formando o edema. Mas, apesar das inúmeras semelhanças, os padrões clínicos das doenças do CGEF se diferenciam em alguns aspectos, como região afetada do corpo, níveis de prurido e de dor (CERDEIRO et al., 2015; LARSSON; LUCAS, 2016; MAZZOTTI; ROZA, 2016). As manifestações clínicas podem ser crônicas e recorrentes, especialmente se a causa de base não for descoberta e controlada (BUCKLEY; NUTTALL, 2012). 


\section{Granuloma eosinofílico}

É a principal doença do CGEF (LITTLE, 2012) e pode ter diferentes apresentações, com padrão cutâneo, mucocutâneo e/ou acometer a cavidade oral de gatos. Frequentemente tem causa idiopática e hereditária (MILLER et al., 2013). Quando de etiologia hereditária, a sintomatologia geralmente inicia-se de quatro a 18 meses de idade e se resolve espontaneamente até os quatro anos (ROSYCHUK, 2011).

O GE pode ocorrer em vários locais do corpo, como: lábio inferior, queixo, língua, região tonsilar, frênulo, palato duro ou mole, laringe, ponte nasal, pavilhões auriculares, porção caudal das coxas e coxins podais (SANDOVAL et al., 2005; ROSYCHUK, 2011; MILLER et al., 2013). Pode haver uma ou mais lesões, localizadas em uma região bem delimitada com alopecia (LEE GROSS et al., 2005; BLOOM, 2006).

As formas cutâneas e mucocutânea caracterizam-se por lesões únicas, formando placas lineares ou tumefações papulares, nodulares a ovais, firmes ou edematosas, bem definidas, elevadas, com coloração que pode variar de eritematosa, amarelo alaranjada a salmão. É comum ter áreas de alopecia, mas quando iniciais, as lesões ainda podem conter pelos (HNILICA, 2011; BUCKLEY; NUTTALL, 2012; MILLER et al., 2013). Também pode afetar os coxins digitais com crostas, ulceração focal, alopecia interdigital e eritema, causando dor e claudicação nos animais acometidos (NESBITT; ACKERMAN, 1998).

Já as lesões em cavidade oral caracterizam-se por erosões ou úlceras, focos necróticos brancos, amarelados na zona ulcerada ou na superfície (BUCKLEY; NUTTALL, 2012; MILLER et al., 2013). Quando muito severas, as lesões ulceradas podem precisar de cirurgia, devido à possibilidade de hemorragia (BUCKLEY; NUTTALL, 2012).

Devido ao aspecto e dependendo da localização, o GE pode causar os seguintes sintomas no gato acometido: anorexia, sialorréia, problemas na preensão dos alimentos, disfagia, mastigação anormal, tosse, halitose; mas também pode ser assintomático, quando na presença de lesões isoladas (NESBITT; ACKERMAN, 1998; LITTLE, 2012; MILLER et al., 2013). Entretanto, mesmo não sendo evidentes, o aumento de eosinófilos no sangue e o aumento de linfonodos geralmente ocorrem junto aos outros sinais clínicos (HNILICA, 2011). O animal pode manifestar muito prurido ou nenhum (FOSTER, 2003; BLOOM, 2006). O GE, além de ser um dos constituintes do CGEF, também pode ser subdividido em três outros tipos: GL, GM e GON.

Granuloma linear: É a forma clássica do GE e recebe esse nome por apresentar placas de configuração linear, espessadas e elevadas, como um cordão, a cor e o tamanho podem variar de amarela a rosada, de 0,5 a $5 \mathrm{~cm}$, respectivamente. Geralmente as lesões localizam-se na parte caudal e medial da coxa, além do pescoço, tórax, membros anteriores e da lateral do tronco, e podem sumir espontaneamente (NESBITT; ACKERMAN, 1998; BUCKLEY; NUTTALL, 2012). Esta forma de granuloma parece ser idiopática e geralmente não está associada a uma doença primária (NORSWORTHY et al., 2009).

Granuloma do Mento: São lesões com forma papular ou nodular que causam edema do lábio inferior e mento. É a principal causa de tumefação, edema e nódulos nessas regiões, popularmente conhecidos por 'lábios gordos' e 'mento gordo' 
(SANDOVAL et al., 2005; ZABEL, 2011). Geralmente esta forma é assintomática e intercorrente (NORSWORTHY et al., 2009).

Granuloma Orofaríngeo Nodular (GON): É uma lesão em forma de nódulo, firme, com coloração que varia de rosada a amarelada e aspecto verrucoso a liso. Esse nódulo pode ser encontrado na orofaringe ou no dorso da língua (Figura 1) (MOTHÉ et al., 2016). Ocorre em gatos adultos e, às vezes, é observado em associação a uma úlcera eosinofílica. Geralmente está associado com reações de hipersensibilidade primária subjacentes, ou seja, alguma reação alérgica, como a dermatite atópica, ou mais frequentemente, a DAPP. Devido a localização dos nódulos, a disfagia e a obstrução respiratória também pode ocorrer (NORSWORTHY et al., 2009; MOTHÉ et al., 2016).

FIGURA 1: Granuloma orofaríngeo nodular sobre a língua de um felino.

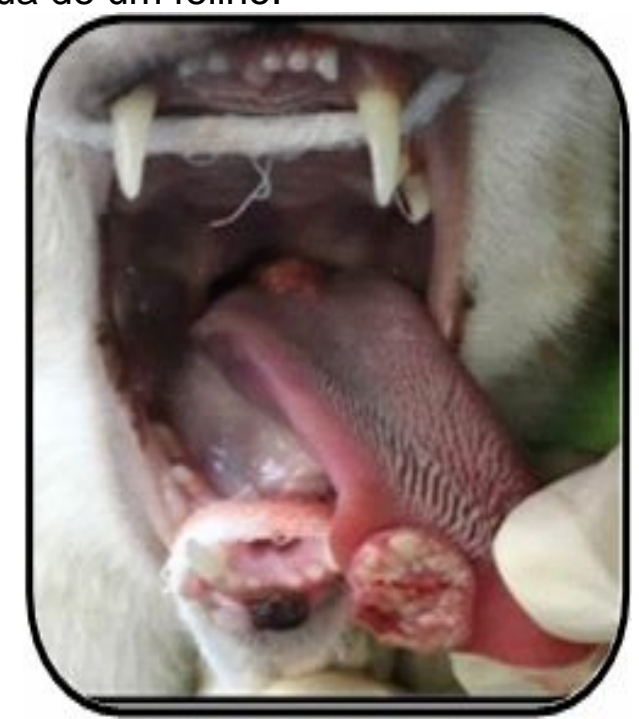

Fonte: MOTHÉ et al., (2016)

Placa eosinofílica

A PE é frequente em gatos (MILLER et al., 2013). A lesão característica pode ser única ou múltipla, caracterizadas por áreas elevadas e bem demarcadas com alopecia, eritema, erosão e ulceração, além de muito prurido (SANDOVAL et al., 2005; BLOOM, 2006; MILLER et al., 2013). As áreas exsudativas e ulceradas podem ter focos esbranquiçados que correspondem a pontos de necrose e podem se infectar secundariamente (MILLER et al., 2013).

As lesões geralmente localizam-se na parte ventral do abdômen (Figura 2), perianal, face medial das pernas, pescoço, axilas (Figura 3), tórax ventral e lateral, região inguinal, interdígitos, mas são vistas em qualquer área do corpo, como as extremidades dos membros pélvicos, junções mucocutâneas, dorso e região dos cotovelos (SANDOVAL et al., 2005; BLOOM, 2006; MILLER et al., 2013). 
FIGURA 2: Felino com lesões elevadas, alopécicas e eritematosas na região do abdômen, diagnosticado com placa eosinofílica.

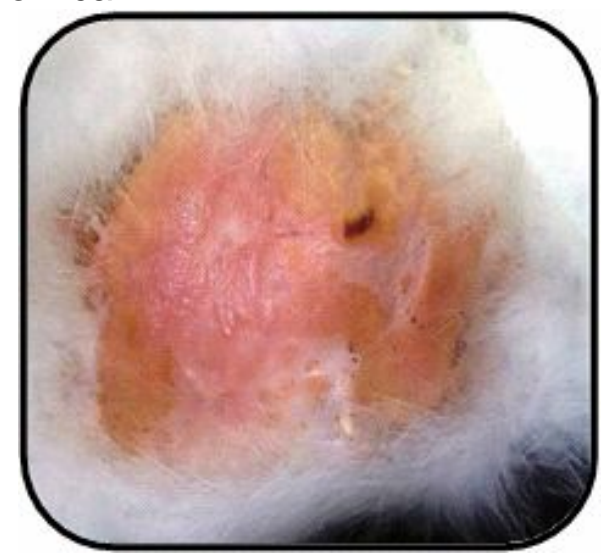

Fonte: Arquivo pessoal

FIGURA 3: Felino com lesões elevadas, alopécicas e eritematosas na região da axila, diagnosticado com placa eosinofílica.

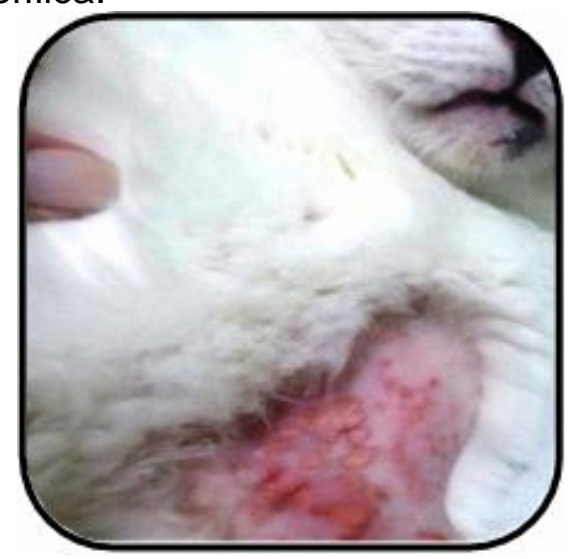

Fonte: Arquivo pessoal

A placa pode ser arredondada a oval ou linear, com tamanho de 0,5 a $7 \mathrm{~cm}$ de comprimento (MILLER et al., 2013). Considera-se que a PE é uma reação alérgica., geralmente é acompanhada por aumento de eosinófilos tanto na circulação, quanto na citologia da lesão (BLOOM, 2006). Também pode ter causa hereditária e nesse caso com resolução espontânea (MILLER et al., 2013).

Os animais com placa eosinofílica apresentam muito prurido e tendem a lamber excessivamente as regiões afetadas, tornando-as úmidas e ocasionando mais lesões por autotraumatismo (BARDAGI; FONDATI, 2012; BUCKLEY; NUTTALL, 2012; MILLER et al., 2013), também apresentam letargia e estresse. 


\section{Úlcera indolente}

Gatos são comumente afetados por UI. As lesões são no lábio superior e se apresentam circunscritas e uni ou bilaterais, principalmente, iniciando-se como uma úlcera pequena, eritematosa e crostosa, que pode evoluir aumentando de tamanho, tornando-se uma área vermelha-acastanhada, alopécica, brilhante, com edema e bordos marcados. Pode ser cutânea, muco cutânea e/ou acometer a cavidade oral (SANDOVAL et al., 2005; MILLER et al., 2013).

O centro da lesão pode ter pontos amarelos e brancos que correspondem a áreas de necrose e que podem se infectar secundariamente (SANDOVAL et al., 2005; HNILICA, 2011; BUCKLEY; NUTTALL, 2012; MILLER et al., 2013). Quando o quadro se agrava, as erosões podem aumentar de tamanho e se aprofundar, inclusive podendo deformar o lábio e a face do animal (SANDOVAL et al., 2005).

A Ul também pode acontecer por trauma mecânico por excesso de lambedura. Raramente acontecem em outras locais, mas podem aparecer na língua, palato mole e duro e se estender para o plano nasal (PATERSON, 2010; MILLER et al., 2013).

Ao contrário da PE, raramente as úlceras causam dor e prurido, sendo assintomáticas, geralmente (MILLER et al., 2013), mas é importante tratar assim que observado, pois podem se tornar uma neoplasia, como o carcinoma epidermóide (SANDOVAL et al., 2005; ZABEL, 2011) que é, inclusive, um dos diagnósticos diferenciais, além de outras doenças (BUCKLEY; NUTTALL, 2012; MILLER et al., 2013).

\section{- DIAGNÓSTICO}

O diagnóstico deve compreender o histórico, a anamnese e a manifestação clínica, ou seja, o aspecto das feridas. Mas, apesar de essenciais, essas etapas não são suficientes para fechar o diagnóstico, que só é realizado com exames complementares, como os exames de citolopatologia e histopatologia cutâneas. Além disso, é imprescindível que a causa do CGEF seja descoberta (BUCKLEY; NUTTALL, 2012; CERDEIRO et al., 2015; LARSSON; LUCAS, 2016; MAZZOTTI; ROZA, 2016).

De forma geral, em relação a citologia e histopatologia, o CGEF apresenta infiltrado eosinofílico intenso na pele e depósito de detritos granulares amorfos (FONDATI et al., 2001). Por isso, o diagnóstico do CGEF é muito sugestivo quando a manifestação clínica é acompanhada da presença de vários eosinófilos na citologia (BUCKLEY; NUTTALL, 2012). O hemograma também pode apresentar eosinofilia periférica (NORSWORTHY et al., 2009).

\section{- DIAGNÓSTICOS DIFERENCIAIS}

Os diagnósticos diferenciais devem ser considerados e independentemente do padrão clínico do CGEF, as doenças mais confundíveis são as seguintes: outros tipos de granulomas causados por bactérias e fungos, herpesvirose ou calicivirose, abscessos, furunculose, complexo gengivite-estomatite-faringite, alergia a insetos, traumas, câncer, dentre outros (FOSTER, 2003; BUCKLEY; NUTTALL, 2012; SANTOS et al., 2016).

Dentre as doenças infecciosas facilmente confundíveis com as formas do complexo granuloma eosinofílico devido às semelhanças nas variáveis manifestações 
clínicas, está a esporotricose (BAZZI et al., 2016; MIRANDA et al., 2018), que merece atenção especial, sobretudo no Brasil, devido a sua alta ocorrência, sendo considerada, inclusive, uma hiperendemia no país (MACEDO-SALES et al., 2018). A esporotricose é uma micose subcutânea causada por fungos do gênero Sporothrix (De BEER, 2016; SILVA, 2016; BONIFAZ; TIRADO-SÁNCHEZ, 2017; GREMIÃO et al., 2017; ALMEIDA et al., 2018), logo, o seu tratamento é completamente distinto do tratamento empregado no CGEF. Caso um felino doméstico esteja com esporotricose mas seja erroneamente tratado para uma das formas do CGEF, o tratamento não só não terá efeito, como também será ainda mais prejudicial à saúde do animal. Por isso, é muito importante a atenção ao diagnóstico correto para a diferenciação dessas e de outras enfermidades (OROFINO-COSTA et al., 2017).

\section{- TRATAMENTO}

O tratamento do CGEF só será eficaz se a doença inicial for descoberta e controlada. O tratamento consiste na utilização de corticoides, antibióticos e, também de fármacos imunomoduladores, utilização de ácidos graxos para suplementar e, ciclosporina $A$ em casos de resistência. Também é possível a cura espontânea em animais novos (MEDLEAU; HNILICA, 2009; LARSSON; LUCAS, 2016; MAZZOTTI; ROZA, 2016) quando a doença primária não é alérgica (FOSTER, 2003).

Uma vez identificada a causa, esta deve ser devidamente controlada para evitar recidivas que são frequentes quando o agente causal não é investigado e eliminado (MARAILLON et al., 2013). Ocasionalmente, ocorre melhora ou mesmo remissão completa apenas com a antibioticoterapia; portanto, é recomendada a tentativa clínica se houver evidência citológica ou histopatológica de pioderma. As opções são doxiciclina, amoxicilina-clavulanato e enrofloxacina (NORSWORTHY et al., 2009).

Corticosteroides sistêmicos têm sido o tratamento mais comumente ministrado para os diferentes padrões clínicos do CGEF. A prednisolona por via oral é o medicamento de eleição dentre os corticóides, especialmente para felinos (HNILICA, 2011; BUCKLEY; NUTTALL, 2012; MOTHÉ et al., 2016).

Como terapêutica secundária, também é possível a utilização de agentes imunomoduladores como levamisol e tiabendazol, e também há referência a utilização de acetato de megestrol, mas sua utilização é muito controversa, podendo ocasionar efeitos adversos indesejáveis e por isso seu uso não é encorajado (HNILICA, 2011).

Suplementar com ácidos graxos e utilizar antibióticos tópicos podem aliviar os sinais e resultar em melhoras. $E$, a ciclosporina $A$ também pode ser uma opção em casos intratáveis resistentes a corticosteroides (NORSWORTHY et al., 2009).

\section{- PROGNÓSTICO}

Na maioria dos casos, o prognóstico é favorável. Contudo, para o sucesso do tratamento e o consequente melhor prognóstico são necessários a descoberta e o controle da doença primária, senão recidivas podem ser frequentes, necessitando de tratamento contínuo ou repetição da terapia. Ou seja, o prognóstico será melhor se forem possíveis a identificação e o tratamento de distúrbio subjacente (NORSWORTHY et al., 2009). 


\section{CONSIDERAÇÕES FINAIS}

Contextualmente, o CGEF faz juz ao nome "complexo", pois mesmo não sendo incomum, suas características ainda são cercadas por mistérios, tais como a etiologia e a patogenia que ainda não são completamente esclarecidas, além do desafio do diagnóstico e do tratamento, cujo sucesso depende da descoberta da causa; caso contrário, as lesões tornam-se refratárias ao tratamento de eleição, ou seja, com falhas terapêuticas. Além disso, o CGEF possui diferentes padrões clínicos e que, inclusive, podem se sobrepor, ocorrendo de forma concomitante. Por isso, o estudo sobre o CGEF é relevante para que este seja reconhecido melhor e mais rapidamente, reduzindo-se, assim, as falhas terapêuticas.

\section{REFERÊNCIAS}

ABBAS, A. K.; LICHTMAN, A. H.; PILLAI, S. Imunologia celular e molecular. 9aㅡ. ed. Brasil: Elsevier, 2019, 576 p.

ALMEIDA, A.; PIMENTEL, M.I.E.; GIORDANO, C. Boletim Epidemiológico Esporotricose 001/2018. Vigilância e cenário epidemiológico: Esporotricose no estado do RJ. Rio de Janeiro: Gerência de Doenças Transmitidas por Vetores e Zoonoses, $2018 . \quad$ Disponível em: http://www.riocomsaude.rj.gov.br/Publico/MostrarArquivo.aspx?C=mgfY3RQJkek\%3D Acesso em 10/10/2020

BARBOSA, A. S.; DEL NERO, B.; AMBROSIO, C. E. Terapia homeopática em dermatopatias de gatos - revisão de literatura. Acta Veterinaria Brasilica, v. 7, n. 1, p. 29-37, 2013. https://doi.org/10.21708/avb.2013.7.1.2950

BARDAGÍ, M.; FONDATI, A. Feline Eosinophilic Granuloma Complex: current knowledge. Proceedings of the European Society of Veterinary Dermatology, Palma de Mallorca, Spain, 2012. https://doi.org/10.1177/1098612X12451549

BLOOM, P. B. Canine and feline eosinophilic skin diseases. Veterinary Clinics of North America Small Animals Practice, v. 36, p. 141-160, 2006. https://doi.org/10.1016/j.cvsm.2005.09.015

BONIFAZ, A.; TIRADO-SÁNCHEZ, A. Cutaneous disseminated and extracutaneous sporotrichosis: current status of a complex disease. Journal of Fungi, v. 3, n. 1, p. 6, 2017. https://doi.org/10.2290/jof3010006

BOURDEAU, P.; FER, G. Characteristics of the 10 most frequent feline skin disease conditions seen in the dermatology clinic at the National Veterinary School of Nantes. Veterinary Dermatology, v. $15, \quad$ p. 67,2004 . https://doi.org/10.1111/j.13653164.2004.00414_67.x

BRITO, A. L. Complexo granuloma eosinofílico em cães e gatos. Monografia, Universidade Federal da Paraíba, 2017. Disponível em: 
https://repositorio.ufpb.br/jspui/bitstream/123456789/4149/1/ALLB11042018.pdf Acesso em: $20 / 05 / 2020$

BUCKLEY, L.; NUTTALL, T. Feline eosinophilic granuloma complex - some clinical carification. Journal of Feline Medicine and Surgery, v. 14, n. 1, p. 471- 481, 2012. https://doi.org/ 10.1177/1098612X12451549

CERDEIRO, A. P. S.; FAM, A. L. P. D.; FARIAS, M. R. Complexo granuloma eosinofílico em felinos domésticos. Medvep Dermato - Revista de Educação Continuada em Dermatologia e Alergologia Veterinária, v. 3, n. 11, p. 330-335, 2015. Disponível em: https://medvep.com.br/wp-content/uploads/2020/09/Complexo-granulomaeosinof\%C3\%ADlico-em-felinos-dom\%C3\%A9sticos.pdf Acesso em 05/10/2020

COLOMBINI, S.; HODGIN, E. C.; FOIL, C. S.; HOSGOOD, G.; FOIL, L. D. Induction of feline flea allergy dermatitis and the incidence and histopathological characteristics of concurrent indolent lip ulcers. Veterinary Dermatology, v. 12, p. 155-161, 2001. https://doi.org/10.1046/j.1365-3164.2001.00243.x.

CONCEIÇÃO-SILVA, F.; MORGADO, F. Immunopathogenesis of human sporotrichosis: what we already know. Journal of Fungi, v. 4, n. 3, p. 89, 2018. https://doi.org/10.3390 / jof4030089

DE BEER, Z.W.; DUONG, T.A.; WINGFIELD, M.J. The divorce of Sporothrix and Ophiostoma: solution to a problematic relationship. Studies in Mycology, v. 83, p. 165191, 2016. https://doi.org/ 10.1016 / j.simyco.2016.07.001

FEITOSA, F. L. F. Semiologia da pele. In: LUCAS, R. (Ed.) Semiologia Veterinária - a arte do diagnóstico. São Paulo: Roca, cap.12, p. 641- 676. 2004.

FONDATI, A.; FONDEVILA, D.; FERRER, L. Histopathological study of feline eosinophilic dermatoses. Veterinary Dermatology, v. 12, n. 1, p. 333-338, 2001. https://doi.org/ 10.1046/j.0959-4493.2001.00253.x.

FOSTER, A. Clinical approach to feline eosinophilic granuloma complex. In: Veterinary Practice, v. 25, p. 2-9, 2003. http://dx.doi.org/10.1136/inpract.25.1.2

GELBERD, H. B.; LEWIS, R. M.; FELSBURG, P. J., SMITH, C. A. Antiepithelial autoantibodies associated with the feline eosinophilic granuloma complex. American Journal of Veterinary Research, v. 46, p. 263-265, 1985 . Disponível em: https://pubmed.ncbi.nlm.nih.gov/3882029/ Acesso em 09/10/2020

GREMIÃO, I.D.F.; MIRANDA, L.H.M.; REIS, E.G. et al. Zoonotic epidemic of sporotrichosis: cat to human transmission. SHEPPARD, D.C., editor. PLoS Pathogens, v. 13, n. 1, 2017. https://doi.org/10.1371 / journal.ppat.1006077 
HASAN, J. A.; WOLKMER, P.; MARTINS, P.; BATISTA, M.; MAIDANA, F. M.; DOS REIS, D. M. Relato de caso de granuloma eosinofílico em Rotweiller. Archives of Veterinary Science, v. 21, supl 00, p. 437-439, 2016.

HILL, P. B.; LO, A.; EDEN, C. A. N.; HUNTLEY, S.; MOREY, V.; RAMSEY, S. Survey of the prevalence, diagnosis and treatment of dermatological conditions in small animals in general practice. Veterinary Record, v.158, p. 533-539, 2006. https://doi.org/10.1136/vr.158.16.533

HNILICA, K. Small Animal Dermatology. A Color Atlas and Therapeutic Guide (3 ${ }^{a}$ Ed.). St. Louis, Missouri: Elvesier Saunders, 2011, 611p.

LARSSON, C. E.; LUCAS, R. Tratado De Medicina Externa - Dermatologia Veterinária. São Paulo: Interbook editorial, 888p, 2016.

LEE GROSS, T.; IHRKE, P. J.; WALDER, E. J.; AFFOLTER, V. K. Spongiotic and vesicular disease of the epidermis. Nodular and diffuse diseases of the dermis with prominent eosinophils, neutrophils, or plasma cells. In: LEE GROSS, T. Skin diseases of the dog and cat: clinical and histopathologic diagnosis, v. 1, 2a ed, Oxford, p. 105-116 e 342-373, 2005.

LITTLE, S. The Cat-Clinical Medicine and Management ( $1^{a}$ Ed). St Louis, Missouri: Elsevier, 2012, 261p.

MACÊDO-SALES, P.A.; SOUTO, S.R.L.S.; DESTEFANI, C.A. et al. Domestic feline contribution in the transmission of Sporothrix in Rio de Janeiro State, Brazil: a comparison between infected and non-infected populations. BMC Veterinary Research, v. 14, p. 1-19, 2018. https://doi.org/10.1186 / s12917-018-1340-4

MARAILLON, R.; LEGEAY, Y.; BOUSSAIRE, D.; SENECAT, O. Manual elsevier de veterinária, 7 ed, São Paulo: Elsevier, 2013, 1008p.

MAZZOTTI, G. A.; ROZA, M. R. Medicina felina essencial: guia prático. Curitiba: Equalis, 998p, 2016.

MEDLEAU, L.; HNILICA, K. A. Dermatologia de pequenos animais: Atlas Colorido e Guia Terapêutico. In: Miscelânea de enfermidades cutâneas em gatos. São Paulo: Roca, 2009. Cap. 15, p. 249-262.

MILLER, W.; GRIFFIN, C.; CAMPBELL, K. Muller \& Kirk's - Small Animal Dermatology (7ª Ed.). St Louis, Missouri: Elsevier, 2013, 948p.

MORIELLO, K. A.; KUNKLE, G.; MILLER, L. M., CROWLEY, A. Lack of autologous tissue transmission of eosinophilic plaques in cats. American Journal of Veterinary 
Research, v. 51, p. 995-998, 1990. Disponível em: https://pubmed.ncbi.nlm.nih.gov/2389898/ Acesso em: 17/08/2020

MOTHÉ, G. B.; VALPASSOS, M. B.; MATTOS, A. S.; MACIEIRA, D. B. Granuloma orofaríngeo nodular em gato: Relato de caso. Enciclopédia Biosfera, v. 13, n. 24, p. 572-579, 2016. https://doi.org/10.18677/EnciBio_2016B_053

NESBITT, G.; ACKERMAN, L. Canine and Feline Dermatology - Diagnosis and Treatment. New Jersey: Veterinary Learning Systems, 1998, 498p.

NORSWORTHY, G. D.; CRYSTAL, M. A.; GRACE, S. F.; TILLEY, L. P. O paciente felino (3 Ed). São Paulo: Roca, 2009, 824p.

OROFINO-COSTA, R.; MACEDO, P.M.; RODRIGUES, A.M. et al. Sporotrichosis: an update on epidemiology, etiopathogenesis, laboratory and clinical therapeutics. Anais Brasileiros de Dermatologia, v. 92, n.5, p. 606-620, 2017. https://doi.org/10.1590/abd1806-4841.2017279

PATERSON, S. Manual de Doenças da Pele do Cão e do Gato (2a Ed.). Rio de Janeiro, Brasil: Guanabara Koogan, 2010, 294p.

POWER, H. T. Eosinophilic granuloma in a family of specific pathogen-free cats. Proceedings of the American Academy of Veterinary Dermatology / American College of Veterinary Dermatology, v. 6, p. 45, 1990. https://doi.org/10.1177/1098612X12451549

POWER, H. T.; IHRKE, P. J. Selected feline eosinophilic skin diseases. Veterinary Clinics of North America: Small Animal Practice, v. 25, p. 833-850, 1995. https://doi.org/10.1016/S0195-5616(95)50130-5

ROSYCHUK, R. Heads up! Challenging skin diseases of the feline head. Proceedings of the 36th World Small Animal Veterinary Congress, Jeju, Korea, 2011. Disponível em: $\quad$ https://www. vin.com/apputil/content/defaultadv1 .aspx? $\mathrm{id}=5124295 \& \mathrm{pid}=11343$ Acesso em: 13/08/2020

SANDOVAL, J. G.; ESMERALDINO, A.; RODRIGUES, N. C.; FALLAVENA, L. C. B. Complexo granuloma eosinofílico em felinos: revisão de literatura. Veterinária em Foco, v. 2, n. 2, p. 109-119, 2005. Disponível em: http://www.periodicos.ulbra.br/index.php/veterinaria/issue/archive Acesso em: 05/07/2020

SANTOS, A. C. P. S. Tricograma como método de diagnóstico dermatológico para avaliar a presença de prurido em gatos. Dissertação de mestrado, Universidade Lusófona de Humanidades e Tecnologias, Lisboa, Portugal, 2013. Disponível em: https://recil.grupolusofona.pt/bitstream/10437/4776/1/Disserta\%c3\%a7\%c3\%a3o\%20de 
\%20Mestrado\%20Final\%20-\%20Ana\%20Cl\%c3\%a1udia\%20Santos.pdf Acesso em: $20 / 05 / 2020$

SANTOS, B.; REQUICHA, J. F.; PIRES, M. A.; VIEGAS, C. Complexo gengiviteestomatite-faringite felino: a doença e o diagnóstico. Revista Lusófona de Ciência e Medicina Veterinária, v.8, p. 18-27, 2016. Disponível em: https://revistas.ulusofona.pt/index.php/rlcmv/article/view/5705\#: :text=0\%20Complexo \%20Gengivite\%2DEstomatite\%2DFaringite, idade\%2C\%20n\%C3\%A30\%20havendo\%2 Opredisposi\%C3\%A7\%C3\%A3o\%20sexual. Acesso em: 21/07/2020

SCOTT, D. W.; MILLER, W. H.; ERB, H. N. Feline dermatology at Cornell University: 1407 cases (1988-2003). Journal of Feline Medicine and Surgery, v. 15, n. 4, p. 307316, 2012. https://doi.org/10.1177/1098612X12468922

SILVA, J. N. Avaliação da sensibilidade de métodos diagnósticos e da carga fúngica durante o tratamento com itraconazol na esporotricose felina. Tese Universidade Federal do Rio Grande do Sul, 109p, 2016.

TAGLINGER, K.; DAY, M. J.; FOSTER, A. P. Characterization of inflammatory cell infiltration in feline allergic skin disease. Journal of Comparative Pathology, v. 137, n. 2, p. 211-223, 2007. https://doi.org/10.1016/j.jcpa.2007.07.001

ZABEL, S. Common Feline Dermatologic Diseases-Eosinophilic Granuloma Complex. Proceedings of the 36th World Small Animal Veterinary Congress, Jeju, Korea, 2011. em:

https://www.vin.com/apputil/content/defaultadv1 aspx?pld=11343\&catld=34561\&id=518 9558 Acesso em: 15/05/2020 